\title{
Pulmonary function development in children with past history of asthma
}

\author{
Toshio Nakadate, Jun Kagawa
}

\begin{abstract}
Study objective-The aim was to examine whether or not the children with a past history of asthma but free from asthmatic attacks for several years show a different growth pattern in pulmonary function from control children.
\end{abstract}

Design-A community based cohort was surveyed three times during a four year follow up period.

Setting-Kashima district in Ibaraki prefecture, Japan.

Participants-In 1980, 441 primary school children between 113 and 124 months of age were enrolled as an initial cohort; 325 of these provided reliable results in each of the three surveys.

Main results $-A$ level and a slope of FVC, $\mathrm{FEV}_{1}, V_{\max } 50$, and $V \max 25$ were calculated for each child, based on a general linear model analysis. Past histories of each child were determined from a standardised questionnaire. The children with a history of doctor diagnosed asthma showed a lower $\checkmark m a x 50$ level $(p<0.005)$ and a lower level and slope of $V \max 25(p<0.005, p<0.01)$ than control children, even when only those who did not suffer from wheezing attacks during the follow up period were considered.

Conclusions-Indices of peripheral airways function in children with an asthmatic history were reduced even if they had been in remission for several years. The difference in pulmonary function in comparison to control children might become greater at the time of the adolescent growth spurt.

$\mathcal{f}$ Epidemiol Community Health 1992; 46: 437-442

Despite many studies over the years, the natural history of asthma has not been fully described. ${ }^{1}$ From an epidemiological point of view, one of the unresolved issues is whether or not children with a history of asthma but free from asthmatic attacks for several years show growth of lung function comparable with normal children.

In a recent large cohort study, ${ }^{2}$ Kelly et al observed that about $30 \%$ of subjects with the history of wheezing in childhood but without wheezing symptoms in early adulthood experienced subsequent attacks of wheezing. They suggested that those subjects might possibly be diagnosed as having asthma of adult onset. Their results indicated that children with a wheezing history might show a different growth pattern of pulmonary function from normal children.
However, few studies have evaluated such growth patterns through longitudinal measurements of lung function in asthmatic children.

We followed up school children over four years using forced vital capacity manoeuvre measurements and compared the evolution of these measurements between children with a history of asthma and those without.

\section{Methods}

The subjects were school children from seven elementary schools in Kashima district of Ibaraki prefecture, Japan. Four schools were selected from areas neighbouring an industrial area and three were located $10-15 \mathrm{~km}$ north of the industrial areas. The children were on the school registers as fourth year students on September 1, 1980 , and were born and brought up in the Kashima district. The ages of the children from the two areas were equally distributed between 9.4 and 10.3 years.

After exclusion of children who moved from other districts because of probable differences in social and family background which might affect growth in comparison with children born and raised in the district, the study group consisted of 217 schoolboys and 224 schoolgirls. We examined height, weight, pulmonary function, respiratory symptoms, past history of respiratory illness, and other familial factors in September 1980, as an initial survey, and again two and four years later (September 1982, and September 1984).

At each school, maximum expiratory flowvolume curves were measured using a 10 litre water sealed spirometer (Pulmocorder FV R-1775, Anima Co, Japan). The deviation of the plastic bell of the spirometer was electrically calculated after transformation to voltage by a potentiometer connected to the spirometer. The flow was also calculated from the electrical differentiation of this voltage. The volume and flow data were fed into a computer after A-D conversion, after which the forced vital capacity (FVC), forced expiratory volume in one second $\left(\mathrm{FEV}_{1}\right)$, and maximum expiratory flow rates at $50 \%$ and $25 \%$ of FVC ( $\max$ max,$\left.V_{\max } 25\right)$ were calculated.

The subjects were instructed to repeat the FVC manoeuvres in a standing position until acceptable values were obtained on three occasions. The manoeuvre was repeated at most seven times. Nose clips were not used because an open circuit method was employed. Whether or not each manoeuvre was acceptable was evaluated according to the criteria of the American Thoracic Society, ${ }^{3}$ based on the measured values, and on 
the shape of flow-volume and flow-time curves. In each survey, the subjects who completed acceptable FVC manoeuvres at least twice were considered to provide reliable pulmonary function results. The figures for each variable used for the analysis were those of the manoeuvre in which the sum of FVC and $F E V_{1}$ was the maximum. To minimise bias in the measurement, all examinations were carried out by one examiner with the same apparatus throughout all the surveys. Immediately before the measurements of flow-volume curves, standing height and body weight of the subjects were measured in stockinged feet, without heavy clothing, using the same apparatus throughout all the surveys.

A standardised questionnaire, the Japanese version of an ATS-DLD-78-C questionnaire, ${ }^{4}$ was distributed to the parents of the children at the time of the pulmonary function tests, and information about respiratory symptoms, past history of respiratory illness, smoking status of family members, and other home background factors was obtained. According to the responses to the questionnaire, subjects were divided into the following three categories: category A: those who had been diagnosed by doctors as having asthma at the initial survey; category B: those who did not belong to category A but who had been diagnosed by doctors as having bronchitis or pneumonia at the initial survey; category $C$ : those who had no past history of asthma, bronchitis, pneumonia, or admission to a hospital for other respiratory troubles, either at the initial survey or during the follow up period.

Those of the children in category $A$ who showed no evidence of wheezing or need for specific medical treatment during the follow up period were referred to as category $\mathrm{A}^{\prime}$.

Of the 441 subjects, 22 moved to another district during the folluw up period, and 24 were absent from school or were suffering from respiratory illnesses at one or more of the surveys. Seventy children were excluded from the analysis because the reproductibility of their FVC manoeuvres at one or more of the surveys was not acceptable. As a result, 325 children ( 165 boys and 160 girls) provided reliable data at all three surveys.

Preliminary analysis showed a good fit of the following model to the distribution of the data in both boys and girls:

$$
\begin{gathered}
F i j=a+B i+C j+d j \star H T i j+e i j \\
(i=1 \sim 325, j=1,2,3)
\end{gathered}
$$

Where $F i j=$ pulmonary function of subject $i$ on survey $j ; a=$ intercept; $B i=$ main effect of subject $i$ $(\Sigma B i=0) ; C j=$ main effect of survey $\mathrm{j}(\Sigma C j=0)$; $d j=$ partial regression coefficients of height on survey $j$; HT $i j=$ height of subject $i$ on survey $j$; and, $e i j=$ residual of subject $i$ on survey $j$ $\left[e i j \sim \mathrm{N}\left(0, \sigma^{2}\right)\right]$

Coefficients of determination of this model were more than 0.95 for $F V C$ and $F E V_{1}$, and were about 0.9 for $V \max 50$ and $V \max 25$ in both boys and girls. Since the model did not include a gender variable, we fitted the model to the data separately for boys and girls, and calculated two indices of the growth pattern of pulmonary function for each child, after Berkey et al. ${ }^{5}$ One was the level, which was defined as $B i$, and the other was slope. In order to obtain the slope, residuals of pulmonary function indices in the model at the three surveys were regressed on time for each subject. Slope was then defined as the change of residuals per year, estimated from the regression equation. The level showed the average difference from the mean of subsamples by gender, and the slope indicated the relative degree of growth during the follow up period. When the slope was zero, the growth of pulmonary function of the individual was considered equal to the mean growth of subsamples by gender.

Statistical analysis was undertaken using the SAS package programs. The GLM procedure was employed in the regression analysis and for comparison of the levels and the slopes by analysis of variance (ANOVA).

\section{Results}

Of 325 children who provided reliable pulmonary function data at all three surveys, 312 belonged to one of the three past history categories. As shown in table $\mathrm{I}$, there were 26 children in category $\mathrm{A}$ $(8 \%)$ and 38 in category B $(12 \%)$. We excluded the remaining 13 of the original sample of 325 children from the following comparison since they had a history of respiratory illnesses other than asthma, bronchitis, or pneumonia at the initial survey, or suffered from asthma, bronchitis, or pneumonia during the follow up period for the first time of their life. In category A, four children had wheezing attacks or took treatment during the follow up period. Therefore the number of children in category $A^{\prime}$ was 22 . Asthma began before age 2 years in 11 children in category $A$, between 3 and 6 years of age in 10 children, and between 7 and 9 years in five children. The mean age of onset asthma was 3.9 years in category $\mathrm{A}$. The mean age at the last asthmatic attack in category $A^{\prime}$ was $5 \cdot 7$ years. No significant sex differences were seen in the distribution of past history categories.

\begin{tabular}{|c|c|c|c|c|}
\hline & \multicolumn{3}{|c|}{ Category } & \multirow[b]{2}{*}{ Other } \\
\hline & $\overline{A\left(A^{\prime}\right)}$ & $B$ & $C$ & \\
\hline $\begin{array}{l}\text { Boys } \\
\text { Girls }\end{array}$ & $\begin{array}{l}11(8) \\
15(14)\end{array}$ & $\begin{array}{l}17 \\
21\end{array}$ & $\begin{array}{l}128 \\
120\end{array}$ & $\begin{array}{l}9 \\
4\end{array}$ \\
\hline Total & $26(22)$ & 38 & 248 & 13 \\
\hline
\end{tabular}

Table I Numbers of children by their past history.

The distribution of the levels and slopes of pulmonary function is shown in the figure by gender. Since the fitting of the model was carried out separately by gender, the means of the levels and slopes were equal to zero in both boys and girls. Comparison of the levels and slopes was undertaken by two way ANOVA which included the past history category and gender as independent variables. Since no significant interaction between the category and gender was observed in any index, the means of the levels and slopes were compared between the categories by Scheffe's multiple comparison method. In table II, means, $95 \%$ confidence intervals, and results of statistical 
Table II Comparison of mean values of the levels and the slopes of pulmonary function tests by ANOVA, using Scheffe's multiple comparison between the past history categories. Lower and upper $95 \%$ confidence intervals are shown in parentheses
Distribution of the levels and the slopes of pulmonary function indices estimated by the general linear model. stratified by gender. Filled bar= boys; hatched bar $=$ girls.

Units: $F V C=m l$;

$F E V_{1}=m l$;

$V \max 50=m l / s$

$V \max 25=m l / s$ tests of the levels and slopes of pulmonary

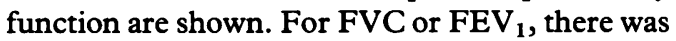
no significant difference in the levels or slopes between any pair of past history categories. On the other hand, the level of $V \max 50$ and the level and slope of Vmax 25 of children in category A were significantly lower than those of children in category $\mathrm{C}$. When the children with a history of asthma but without any wheezing episodes or asthma treatment during the follow up period (category $\mathbf{A}^{\prime}$ ) were compared with other categories, the result was almost the same as for category $\mathrm{A}$ as a whole.

Table III showed prevalences of chronic respiratory symptoms in the children in category $\mathrm{A}^{\prime}$ and category $C$. For each symptom, children who gave an affirmative response at least once in the three surveys were counted. Although the prevalences were higher in category $A^{\prime}$ than in category $\mathrm{C}$, the absolute number of children with chronic symptoms was quite small: three children with chronic cough, and only one child with chronic wheeze.

Some of the children who were excluded from analysis provided acceptable measurements of pulmonary function at one or two of the three surveys. Those acceptable measurements of pulmonary function were compared with the values of children included in the analysis. The distribution of height and age were also compared. As shown in table IV, FVC and $\mathrm{FEV}_{1}$ tended to be large in children included in the analysis, but $\checkmark \max 50$ and $V \max 25$ tended to be large in children excluded from analysis. The result of statistical

\begin{tabular}{|c|c|c|c|c|}
\hline & \multicolumn{2}{|l|}{ Category $A$} & \multirow[t]{2}{*}{ Category $B$} & \multirow[t]{2}{*}{ Category $C$} \\
\hline & Total & $A^{\prime}$ only & & \\
\hline $\begin{array}{l}F V C \\
F E V_{1} \\
V_{\max 50} \\
V_{\max 25}\end{array}$ & $\begin{array}{c}66(-84,215) \\
-76(-213,61) \\
-583(-988,-178)^{\star \star t \dagger} \\
-438(-732,-144)^{\star \star t+T}\end{array}$ & $\begin{array}{l}69(-94,232) \\
-62(-211,88) \\
-546(-987,-105)^{\star \star \dagger} \\
-413(-734,-93)^{\star \star t \dagger t}\end{array}$ & $\begin{aligned} & \text { els } \\
& 6(-117,130) \\
& 14(-99,128) \\
&-11(-345,324) \\
& 62(-182,305)\end{aligned}$ & $\begin{array}{c}1(-48,49) \\
16(-29,60) \\
85(-46,216) \\
49(-46,144)\end{array}$ \\
\hline $\begin{array}{l}\text { FVC } \\
F E V_{1} \\
V_{\max 50} \\
V \max 25\end{array}$ & $\begin{aligned} & 16(-22,55) \\
- & 12(-44,20) \\
- & 63(-152,25) \\
- & 79(-150,-9)^{\star \star}\end{aligned}$ & $\begin{array}{c}20(-21,62) \\
-6(-41,29) \\
-50(-146,46) \\
-67(-144,10)^{\star}\end{array}$ & $\begin{array}{r}1(-31,33) \\
1(-26,27) \\
17(-56,90) \\
-1(-59,57)\end{array}$ & $\begin{array}{c}-2(-14,11) \\
2(-9,12) \\
3(-25,32) \\
8(-15,31)\end{array}$ \\
\hline
\end{tabular}

For the comparison between categories, the two way ANOva model was used which includes sex and the past history category as For the comparison between categories, the two way ANOvA model was used which includes sex and the past history category as
independent factors. Category A was compared with category B and C in two ways: the results including all children in category A are
shown in the column titled "Total", and the results including only the children in subcategory $A$ ' are in the column titled " $A$ ' only". shown in the column titled "Total", and the results including only Units: FVC $=\mathrm{ml} ; \mathrm{FEV} \mathrm{I}_{\mathrm{i}}=\mathrm{ml} ; \mathrm{Vmax} 50=\mathrm{ml} / \mathrm{s} ; \max 25$

$t \mathrm{p}<0.05, \mathrm{ttp}<0.01, \mathrm{tttp}<0.005$ for difference from category $B$
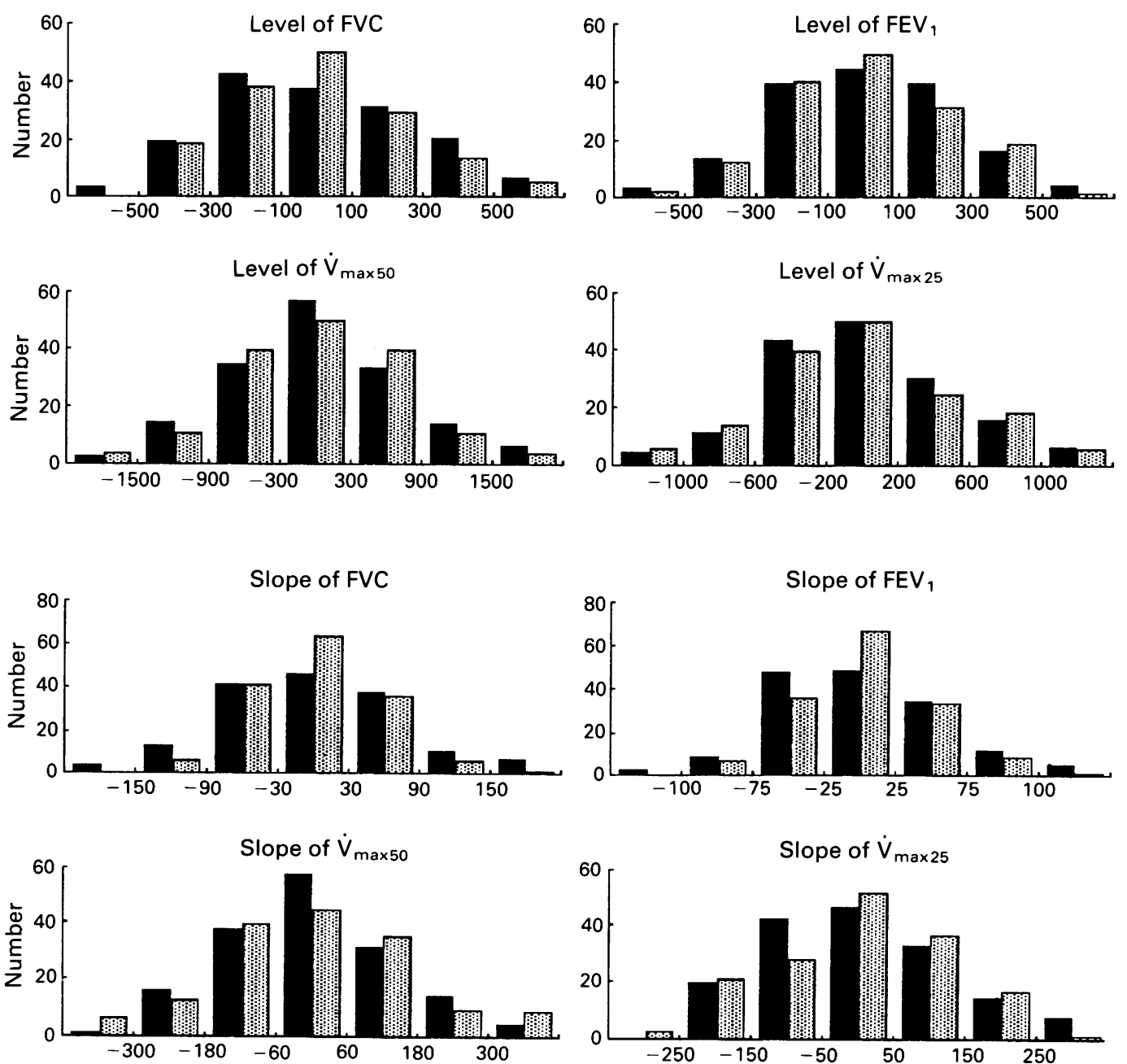
test, however, reached significance $(p<0.05)$ only in the $V \max 50$ values for girls in the second survey. There was no significant difference in the height and age between the two groups.

Four possible confounding factors were considered: residence near to the factory area, paternal smoking, maternal smoking, and use of kerosene or gas heating without a vent pipe. The first of these relates to environmental air pollution, and the others to indoor air quality. Table $\mathrm{V}$ is a cross tabulation of these factors and the past history categories. The percentage of children with a smoking mother was lowest in category $\mathrm{A}$ Although the other three factors were most frequently found in category $\mathrm{A}$, no value of the $\chi^{2}$ statistic was significant, suggesting that these factors were independent of past history categories.

\section{Discussion}

Asthma is one of the commonest peadiatric diseases presenting with wheezing and dyspnoea, and pulmonary function changes caused by the disease have been well described. However, the development of pulmonary function in patients in remission is not so clear. ${ }^{6-8}$ This is because many studies which have examined this issue have used a cross sectional design, and because the subjects of these studies did not form a sample of a definite population but were patients of specific hospitals or clinics. In a population based study, Yarnell and Leger ${ }^{9}$ performed a cross sectional investigation on children aged between seven and 11 years and observed a significant decrease in $\mathrm{FEV}_{0.75}$ and $\mathrm{FEV}_{\mathbf{0}} .75 \%$ in the children who had a past history of asthmatic attacks within one year prior to the investigation. In addition, they reported that there was no difference in FEV values in children with a past history of asthma more than one year before the investigation. These results suggested that functional change due to asthmatic

Table III Prevalence of chronic respiratory symptoms in categories $A^{\prime}$ and $C$.

\begin{tabular}{lll}
\hline & \multicolumn{2}{c}{ Category } \\
\cline { 2 - 3 } & $A^{\prime}$ & $C$ \\
\hline Cough apart from colds & $3(13 \%)^{\mathrm{a}}$ & $3(1 \%)$ \\
Phlegm apart from colds & 0 & $7(3 \%)$ \\
Wheeze apart from colds & $1(5 \%)$ & $1(0.4 \%)$ \\
Any of these three symptoms & $4(18 \%)$ & $11(4 \%)$ \\
\hline a Number and percentage of children who gave affirmative
\end{tabular}

attacks in childhood is fully reversible and that catch up growth in pulmonary function can be observed in one year or so, once the children are in remission.

In a population based longitudinal study in Melbourne, Kelly et $a l^{2}$ reported that children who had had a history of asthma but had been free from wheezing symptoms for at least three years did not show significant difference in FVC, $\mathrm{FEV}_{1}$, or MMEF compared with controls. Their findings are compatible with those of Yarnell and Leger. However, they also pointed out that recurrence of wheezing attacks was seen at 28 years of age in $31 \%$ of subjects who had had mild wheezing episodes in early childhood but no wheezing symptoms at 21 years of age. These results suggested the possibility that there might be some alteration in pulmonary function growth patterns during the follow up period in these subjects.

Children of category $\mathrm{A}^{\prime}$ of this study did not have asthmatic epsiodes or treatment during the follow up period, and only a few had chronic respiratory symptoms. Mean age of onset of asthma was 3.3 years and 5.7 years for the last attack in this group. Therefore children of this group were considered to have been in remission for several years. Children in category $\mathrm{A}^{\prime}$ showed significantly lower levels of $V \max 50$ and $V \max 25$ than controls (category $\mathrm{C}$ ) although FVC and $\mathrm{FEV}_{1}$ levels were not reduced. With regard to slopes, there was no acceleration of growth in Vmax 50 or $V \max 25$ in category $A^{\prime}$, compared with the controls. Furthermore, the slope of $\checkmark \max 25$ in category $A^{\prime}$ was significantly lower than in the control group. In other words, the children of category $A^{\prime}$ had a lower growth rate of $\checkmark \max 25$ than the control children. These results suggest that pulmonary functional change associated with asthma would not recover even if subjects were free from wheezing episodes for several years. They also suggest that dominant pattern of latent change would be one of peripheral airway abnormality.

Martinez et al $^{10}$ recently measured pulmonary function in infants before any episode of lower respiratory illness, and assessed the relation between their initial pulmonary function and the subsequent incidence of the illness during the first year of life. They found a significantly higher
Table IV Comparison of initial age, height, and pulmonary function indices at each survey, between the children included in the analysis and those excluded from the analysis.

\begin{tabular}{|c|c|c|c|c|}
\hline & \multicolumn{2}{|l|}{ Boys } & \multicolumn{2}{|l|}{ Girls } \\
\hline & Included (n) & Excluded (n) & Included (n) & Excluded (n) \\
\hline Initial age (months) & $118 \cdot 6 \pm 3 \cdot 4(165)$ & $118 \cdot 4 \pm 3 \cdot 2(52)$ & $118 \cdot 3 \pm 3 \cdot 6(160)$ & $118 \cdot 4 \pm 3 \cdot 6(64)$ \\
\hline 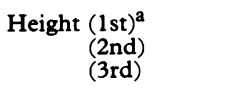 & $\begin{array}{l}134 \cdot 1 \pm 5 \cdot 7(165) \\
145 \cdot 1 \pm 6 \cdot 9(165) \\
159 \cdot 5 \pm 7 \cdot 8(165)\end{array}$ & $\begin{array}{l}134 \cdot 5 \pm 5 \cdot 9(46) \\
144 \cdot 8 \pm 7 \cdot 1(42) \\
159 \cdot 4 \pm 7 \cdot 9(39)\end{array}$ & $\begin{array}{l}134 \cdot 4 \pm 5 \cdot 9(160) \\
146 \cdot 9 \pm 6 \cdot 3(160) \\
154 \cdot 8 \pm 5 \cdot 1(160)\end{array}$ & $\begin{array}{l}134 \cdot 9 \pm 6 \cdot 3(59) \\
147 \cdot 7 \pm 7 \cdot 4(54) \\
155 \cdot 5 \pm 5 \cdot 2(52)\end{array}$ \\
\hline $\begin{aligned} & \text { FVC }(1 \mathrm{st}) \\
& \text { (2nd) } \\
& \text { (3rd) }\end{aligned}$ & $\begin{array}{l}2 \cdot 17 \pm 0.30(165) \\
2 \cdot 65 \pm 0.42(165) \\
3.78 \pm 0.72(165)\end{array}$ & $\begin{array}{l}2 \cdot 10 \pm 0.28(22) \\
2.53 \pm 0.43(31) \\
3.52 \pm 0.66(26)\end{array}$ & $\begin{array}{l}1.96 \pm 0.27(160) \\
2 \cdot 51 \pm 0 \cdot 37(160) \\
3 \cdot 13 \pm 0.40(160)\end{array}$ & $\begin{array}{l}1 \cdot 89 \pm 0.28(21) \\
2 \cdot 47 \pm 0.53(35) \\
3 \cdot 16 \pm 0.50(30)\end{array}$ \\
\hline $\begin{array}{r}\mathrm{FEV}_{1} \text { (1st) } \\
\text { (2nd) } \\
\text { (3rd) }\end{array}$ & $\begin{array}{l}1.96 \pm 0.26(165) \\
2.34 \pm 0.34(165) \\
3.41 \pm 0.60(165)\end{array}$ & $\begin{array}{l}1.85 \pm 0.24(22) \\
2 \cdot 27 \pm 0.36(31) \\
3.30 \pm 0.60(26)\end{array}$ & $\begin{array}{l}1 \cdot 80 \pm 0.25(160) \\
2 \cdot 29 \pm 0 \cdot 34(160) \\
2 \cdot 92 \pm 0.37(160)\end{array}$ & $\begin{array}{l}1 \cdot 78 \pm 0.26(21) \\
2 \cdot 29 \pm 0 \cdot 47(35) \\
2 \cdot 97 \pm 0 \cdot 50(30)\end{array}$ \\
\hline $\begin{aligned} & V \max 50(1 \mathrm{st}) \\
&(\text { (2nd) } \\
& \text { (3rd) }\end{aligned}$ & $\begin{array}{l}3.08 \pm 0.68(165) \\
3.57 \pm 0.78(165) \\
5.00 \pm 1.16(165)\end{array}$ & $\begin{array}{l}2.84 \pm 0.68(22) \\
3.51 \pm 0.73(31) \\
5.08 \pm 0.99(26)\end{array}$ & $\begin{array}{l}2.95 \pm 0.74(160) \\
3.82 \pm 0.90(160) \\
4.51 \pm 0.91(160)\end{array}$ & $\begin{array}{l}3 \cdot 16 \pm 0 \cdot 74(21) \\
4 \cdot 15 \pm 1 \cdot 10(35) \\
4 \cdot 89 \pm 1 \cdot 10^{\star}(30)\end{array}$ \\
\hline $\begin{array}{r}V \max 25 \text { (1st) } \\
\text { (2nd) } \\
\text { (3rd) }\end{array}$ & $\begin{array}{l}1.37 \pm 0.40(165) \\
1.58 \pm 0.51(165) \\
2.58 \pm 0.83(165)\end{array}$ & $\begin{array}{l}1.23 \pm 0.49(22) \\
1.71 \pm 0.50(31) \\
2.86 \pm 0.74(26)\end{array}$ & $\begin{array}{l}1.40 \pm 0.49(160) \\
1.87 \pm 0.66(160) \\
2.57 \pm 0.74(160)\end{array}$ & $\begin{array}{l}1.63 \pm 0.53(21) \\
2.10 \pm 0.70(35) \\
2.81 \pm 0.90(30)\end{array}$ \\
\hline
\end{tabular}

${ }^{2} 1 \mathrm{st}=$ first survey; $2 \mathrm{nd}=$ second survey; $3 \mathrm{rd}=$ third survey

Units: FVC=litres; FEV $1=$ litres; $V \max 50=$ litres/s; $V \max 25=$ litres

${ }^{\star} \mathrm{p}<0.05$ for the difference between children included and those excluded. 
incidence of wheezing illness among the infants who had the lowest pulmonary function indices. Their results cannot be directly compared with ours because the pulmonary function indices used in their study were different from ours. On the basis of their findings, however, our result may be due, at least in part, to difference in pulmonary function before asthma occurred. If that is so, it is suggested that pulmonary function of children tracks from the infantile period to early adolescence. It needs to be determined whether or not reduced pulmonary function in infancy is related to a lowered level of pulmonary function in childhood and early adolescence.

There may be some possible sources of bias in this study. About $20 \%$ of the initial cohort were excluded from analysis because they could not give acceptable data at one or more surveys. Several reports indicated that subjects who could not perform pulmonary function tests acceptably might have different patterns of pulmonary function from others. In this study, indeed, the children excluded from analysis showed lower values of $F V C$ and $F E V_{1}$, and higher values of $\checkmark \max 50$ and $V \max 25$, compared with those included in the analysis. Although the observed difference was small, the exclusion of those subjects from analysis might have biased our results. However, most of the unacceptable measurements in this study were caused by the subjects' inability to perform maximal effort in expiration. Those children who could not perform a maximal expiration on one survey had a tendency to show a similar submaximal expiration pattern on the other surveys. Where there is submaximal expiration, volume measurements usually tend to be small. Moreover, Park ${ }^{11}$ reported the negative effect of effort on the forced expiratory flow measurements. Accordingly, we think that the difference in pulmonary function observed between the two groups was brought about by the difference in the extent of effort in achieving maximal expiration, not by any real difference in pulmonary function.

There are many studies see 12 which have reported a significant association between maternal smoking and reduced pulmonary function in childhood. In this study, however, the frequency of children with a smoking mother was quite low, and the rate was the lowest in category A. Air pollution is also an important factor which might cause a bias to our results. Nevertheless, the annual average concentration of air pollutants has been stable at a low level during the study period: about $0.005 \mathrm{ppm}$ for $\mathrm{SO}_{2}$, and about $0.009 \mathrm{ppm}$ for $\mathrm{NO}_{2} \cdot{ }^{13}$ Futhermore no episodic high concentration of $\mathrm{SO}_{2}, \mathrm{NO}_{2}$, or photochemical oxidants was recorded, even in the factory area, during the

Table $V$ Number and percentage (in parentheses) of several possibly confounding factors by past history categories.

\begin{tabular}{|c|c|c|c|c|c|}
\hline & \multicolumn{3}{|l|}{ Category } & \multirow[b]{2}{*}{$\chi^{2}$} & \multirow[b]{2}{*}{$p$} \\
\hline & $\bar{A}$ & $B$ & $C$ & & \\
\hline $\begin{array}{l}\text { Residence }^{\mathrm{a}} \\
\text { Paternal smoking } \\
\text { Maternal smoking } \\
\text { Home heating }^{\mathrm{b}}\end{array}$ & $\begin{array}{l}21(81 \%) \\
22(88 \%) \\
2(8 \%) \\
18(78 \%)\end{array}$ & $\begin{array}{r}27(71 \%) \\
29(78 \%) \\
4(11 \%) \\
27(75 \%)\end{array}$ & $\begin{array}{r}166(67 \%) \\
188(77 \%) \\
23(9 \%) \\
149(62 \%)\end{array}$ & $\begin{array}{l}2 \cdot 21 \\
1.59 \\
\mathrm{NE} \\
4 \cdot 11\end{array}$ & $\begin{array}{l}0.33 \\
0.45 \\
- \\
0.13\end{array}$ \\
\hline
\end{tabular}

${ }^{2}$ Residence in the neighbourhood of factory area.

Use of paraffin/gas heater without an exhaust pipe.

Children for whom the data on the factor were not available were excluded from calculation of percentage and $\chi^{2}$ value. study period. ${ }^{13}$ On the other hand, the possible influence on pulmonary function growth in childhood of paternal smoking or indoor pollution resulting from home heating facilities has not been made clear, and no significant interaction of these two factors with past history categories was observed in this study. It seems, therefore, unlikely that the differences in pulmonary function level and slope observed in this study were related to difference in these environmental and home factors.

It is well known that a diagnosis of asthma is sometimes difficult to make, especially in infancy, since lower respiratory troubles in infants commonly cause wheezing. It is possible that children suffering from bronchitis or pneumonia accompanied by wheezing were misdiagnosed as having asthma. Since the diagnosis in each child was not confirmed by doctors in the community, we could not evaluate the extent of bias caused by such misdiagnosis. However, the observed difference in pulmonary function between category $\mathrm{A}$ and category $\mathrm{B}$ or $\mathrm{C}$ might be underestimated if category A included examples of such misdiagnosis.

There may be an influence of recall bias when the classification of past history is retrospective. ${ }^{14}$ In other words, when the response to a questionnaire is influenced by the condition of the children at the time of the investigation, leading to the selection of more children in poor health among categories $A$ and $A^{\prime}$, a systematic error may occur. Since categories of past history in this study were defined according to the responses to a questionnaire at the initial survey, the pulmonary function at that time might be biased. Pulmonary function levels in categories $\mathrm{A}$ and $\mathrm{A}^{\prime}$, therefore, might be underestimated compared with controls. Pulmonary function slopes in these children, however, were not considered to be biased because they were independent of individual values of pulmonary function at each survey. Furthermore, category $A^{\prime}$ did not include children who reported recurrence of wheezing attacks or asthma treatment during the follow up period, and only a small proportion of this group had chronic respiratory symptoms. An important finding of this study was that children with a history of asthma but who had been free from wheezing attacks for several years showed poorer growth of forced expiratory flow than controls. It seems unlikely that a large error due to recall bias could influence this finding.

In conclusion, this study indicated that children who had a history of asthma but were in remission for several years showed lower levels and slopes of pulmonary function compared with control children. Large differences were seen in $V \max 50$ and Vmax25, which are indices of relatively peripheral

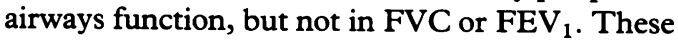
results suggested that changes in peripheral airway function in those children persisted for long periods even when changes in central airways function had resolved. In order to avoid any possible bias due to multiple observers or to variation in measurement apparatus, relatively small numbers of children were enrolled in this study. Furthermore the children were followed up only for four years. Futher longitudinal study is needed to investigate pulmonary function growth 
patterns among children with an asthma history who have been in remission for a long time.

Woolcock AJ, ed. Asthma-what are the importan experiments?' Am Rev Respir Dis 1988; 138: 730-44.

Kelly WJW, Hudson I, Raven J, Phelan PD, Pain MCF Olinsky A. Childhood asthma and adult lung function. $A m$ Olinsky A. Childhood asthma and

3 Fev Respir Dis 1988; 138: 26-30. Ferris BG. Epidemiology standardization project. Recommended standardized procedure for pulmonary function testing. Am Rev Respir Dis 1978; 118.

4 Ferris BG. Epidemiology standardization project. Recommended respiratory disease questionnaires for use with adults and children in epidemiologic research. $\mathrm{Am} \mathrm{Rev}$ Respir Dis 1978; 118: 7-54.

5 Berkey CS, Ware JH, Dockery DW, Ferris BG, Speizer FE. ndoor air pollution and pulmonary function growth in preadolescent children. Am $\mathcal{f}$ Epidemiol 1986; 123: 250-60.

6 Kerrebijn KF, Fioole AC, Bentveld RDW. Lung function in asthmatic children after a year or more without symptoms or treatment. $B M F$ 1978; i: 886-9.

7 Woolcock AJ, Leeder SR, Peat JK, Blackburn CRB. The influence of lower respiratory illness in infancy and childhood and subsequent cigarette smoking on lung function in Sydney school children. Am Rev Respir Dis 1979; 120: 5-14.

8 Martin AJ, Landau LI, Phelan PD. Lung function in young adults who had asthma in childhood. Am Rev Respir Dis 1980 ; 122. 609-16.

9 Yarnell JWG, Leger ASST. Respiratory infections and their influence on lung function in children: a multiple influence on lung function in children: a multiple
regression analysis. Thorax 1981; 36: 847-51.

10 Martinez FD, Morgan WJ, Wright AL, Holberg CJ, Taussig LM. Diminished lung function as a predisposing factor for wheezing respiratory illness in infants. $N$ Engl $f$ Med 1988; 319: 1112-7.

11 Park SU. Effect of effort versus volume on forced expiratory flow measurement. Am Rev Respir Dis 1988; 138: 1002-5.

12 Tager IB, Segal MR, Munoz A, Weiss ST, Speizer FE. The effect of maternal smoking on the pulmonary function of children and adolescents. Am Rev Respir Dis 1987; 136 : 1366-70.

13 Department of Health. Annual report on environment in Ibaraki prefecture 1985. Mito: Department of Health of Ibaraki prefecture, Japan, 1986: 21-35 (in Japanese)

14 Anderson HR, Bland JM, Patel S, Peckham C. The natural history of asthma in childhood. $\mathcal{f}$ Epidemiol Community Health 1986; 40: 121-9.

\section{Miners' lodgings in the nineteenth century. Not good for the lungs.}

The following is the account given by a miner himself of the lodging-places:-

William Eddy, one of the miners, states;-

"I went to work in Greenside four years. Our lodging-rooms were such as not to be fit for swine to live in. In one house there was 16 bedsteads in the room up stairs, and 50 occupied these beds at the same time. We could not always get all in together, but we got in when we could. Often three at a time in the bed, and one at the foot. I have several times had to get out of bed, and sit up all night to make room for my little brothers, who were there as washers. There was not a single flag or board on the lower floor, and there were pools of water 12 inches deep. You might have taken a coal-rake and raked off the dirt and potatoe peelings six inches deep. At one time we had not a single coal. After I had been there two years, rules were laid down, and two men were appointed by the master to clean the house up stairs twice-a-week. The lower apartment was to be cleaned twice-a-day. Then the shop floor was boarded, and two tables were placed in the shop. After that two more shops were fitted up, but the increase of workmen more than kept up with the increased accommodation. The breathing at night when all were in bed was dreadful. The workmen received more harm from the sleeping-places than from the work. There was one pane of glass which we could open, but it was close to a bed-head.

"The mines at Greenside were well ventilated, and in that respect there was nothing to complain of.

"In the winter time the icicles came through the roof, and within 12 inches of the people sleeping in bed. During a thaw, water dropped plentifully into the beds. In the upper beds the person sleeping next to the wall cannot raise his head or change his shirt."

Report to Her Majesty's Principal Secretary of State for the Home Department, from the Poor Law Commissioners on an inquiry into the Sanitary Condition of the labouring population of Great Britain, 1842 